\title{
An Empirical Analysis of Queuing Model and Queuing Behaviour in Relation to Customer Satisfaction at Jkuat Students Finance Office
}

\author{
Sammy Kariuki Mwangi, Thomas Mageto Ombuni \\ Department of Statistics and Actuarial Sciences, Jomo Kenyatta University of Agriculture and Technology, Nairobi, Kenya
}

Email address:

Sirmesammy@gmail.com (S. K. Mwangi)

\section{To cite this article:}

Sammy Kariuki Mwangi, Thomas Mageto Ombuni. An Empirical Analysis of Queuing Model and Queuing Behavior in Relation to Customer Satisfaction at Jkuat Students Finance Office. American Journal of Theoretical and Applied Statistics.

Vol. 4, No. 4, 2015, pp. 233-246. doi: 10.11648/j.ajtas.20150404.12

\begin{abstract}
Over the years, the population of the university has increased with the introduction of double intake system which in turn has led to long waiting times and long queues in students finance department, due to few service stations, inefficiencies in the payment system used and students being disorderly. To enhance service delivery, a proper queuing system is needed. This is achieved by putting in place proper measures to ensure a good flow of students at the service counters. Focusing only on the main queue we collect data and do an empirical analysis of the model in use. Using queuing theory principles and formulas the study showed that on average 22 customers arrive every hour and the service rate is 23.7 customers per hour. The system utilization factor was $92.95 \%$, the probability of zero customers waiting 7.05 ; average number of customers waiting is 12.252 and average waiting time 33.415 min. The study compared the single server model against multi-server model and concluded that $\mathrm{M} / \mathrm{M} / 1$ model was not the best for the Finance department. Using a questionnaire of 384 respondents, the study found out that almost all customers are not satisfied about the nature of waiting lines and some students have turned away at regular occasions due to the long queues. The time students wait to be served should not be overlooked; constant check for their changing needs and improvement in the time spent when serving them has been emphasized by the study. In today's competitive business environment, the modern society is progressively turning into a service dominating one. Customer satisfaction and service operation capabilities have given an organization a competitive advantage in the marketplace and this has consequently led to an increasing importance in service operations management. As a result, waiting has drawn great attention to all business operation management specialists.
\end{abstract}

Keywords: Queue, Behavior, Waiting Time, Logistic Model, Customer Satisfaction

\section{Introduction}

\subsection{Background of Study}

Queues or waiting lines are very common in everyday life whereby certain business situations require customers to wait in line for a service, namely: - telephone exchange, at a bank, in public transportation or in a traffic jam, students waiting to pay school fees, in a supermarket, at a petrol station, at computer systems, waiting to use an ATM machine, and paying for groceries at the supermarket.

Studying how these lines form and how to manage them is called Queuing theory, more generally, queuing theory is concerned with the mathematical modeling and analysis of systems that provide service to random demands which deals with one of the most unpleasant experiences of life, waiting. I have mentioned the telephone exchange first because the first problems of queuing theory were raised by calls and Erlang was the first who treated congestion problems in the beginning of 20th century.

A queuing problem arises when the current service rate of facility falls short of the current service rate of customers.

\subsection{Problem Statement}

A Queuing problem arises when the current service rate of facility falls short of the current service rate demands of customers, in our case when students are reporting at the start 
of semester, when exams are about to begin or before graduation there is usually very long queues at the finance department which has negative consequences to the normal running of the university.

Long queues form at the finance department which could be avoided so as to enhance service delivery. As a result a student spends a lot of time in the queue which he could have used to study or even sometimes is late to lectures since it has taken more time than the student expected.

In all these cases waiting time is of great significance which is influenced by the queuing method in use hence a queuing problem arises and thus an empirical analysis of queuing theory and customer satisfaction analysis is important to be done to try to remedy the existing problem.

\subsection{Justification of the Study}

With the increasing number of students queuing theory becomes an important tool in modeling a system that ensures efficient service delivery at the service counters and satisfaction of the service offered is of great importance to the university and most importantly students. Carrying out an empirical analysis of the model being used is of great importance since the findings will be useful in making administrative decisions. "In today's competitive business environment, the modern society is progressively turning into a service dominating one. Customer satisfaction and service operation capabilities have shown how to provide an organization a competitive advantage in the marketplace and this has consequently led to an increasing importance in service operations management. As a result, waiting has drawn great attention to all business operation management specialists.”(Bonga Wellington Garikai, January 2014.)

\subsection{Significance of the Study}

For businesses and organizations to grow they need to make the correct management decisions at all times and thus decisions on waiting time management are vital in a very competitive business environment whereby waiting time is a factor considered by customers as a measure of service quality.

Many studies have been done in business sector however they are yet to be done in education sector. Hence the study is of relevance since it will add to existing literature on decision making processes with particular reference to university institutions whereby there is very huge demand of university education at the moment with the introduction of double intake system in Kenya. The study can however assist any business in general to improve customer satisfaction especially existing customers as it brings in another dimension that is mostly ignored by many.

\subsection{Hypothesis}

1. $\mathrm{H}_{\mathrm{O}}$ : queuing system $(\mathrm{M} / \mathrm{M} / \mathrm{c})$ used is efficient

$\mathrm{H}_{1}$ : queuing system $(\mathrm{M} / \mathrm{M} / \mathrm{c})$ used is not efficient

2. $\mathrm{H}_{0}$ : Increasing efficiency can raise customer satisfaction.

$\mathrm{H}_{1}$ : There is a negative relationship between efficiency and customer satisfaction.

\subsection{Objectives of the Study}

\subsubsection{General Objective}

To find out how effective the queuing model used when serving students at the finance office is and how it relates to customer satisfaction.

\subsubsection{Specific Objectives}

1. To determine average arrival rate and service rate.

2. To find the average time a student takes in the system and in the queue.

3. To calculate average number of students in the system and in the queue

4. To determine the expected proportion of time the accounts clerks will be idle and System intensity (utilization) or load.

5. To model the queuing behavior in relation to customer satisfaction.

\section{Literature Review}

\subsection{Introduction}

Delays and queuing problems are most common features at our daily-life situations. Queuing theory was born in the early 1900 s with the work of A. K. Erlang of the Copenhagen Telephone Company, who derived several important formulas for teletraffic engineering that today bear his name. Erlang was the first who treated congestion problems caused by telephone calls where the company requested him to work on the holding times in a telephone switch. He identified that the number of telephone conversations and telephone holding time fit into Poisson distribution and exponentially distributed. This was the beginning of the study of queuing theory.

\subsection{Review of Previous Studies on the Subject of Study}

Queuing theory is still widely used in solving network problems namely "The Monitoring of The Network Traffic Based on Queuing Theory."(Palash Sahoo, May, 2011) done in Orissa, India where the author aims to explore how to build the basic model of network traffic analysis based on Queuing Theory.

These problems also arise in more technical environments in manufacturing where they play an important role for business process re-engineering purposes in administrative tasks. "Queuing models provide the analyst with a powerful tool for designing and evaluating the performance of queuing systems." (Bank, Carson, Nelson \& Nicol, 2001)

Queuing theory is also used for queuing analysis to examine multi-stage production line performance to facilitate more realistic resource planning in an industry. Where authors of the paper adopts an analytical approach based on real life data from an international battery company producing battery covers for camera model EC- 
196.( Muhammad Marsudi, Hani Shafeek, Proceedings of the 2014 International Conference on Industrial Engineering and Operations Management Bali, Indonesia, January $7-9$, 2014)

Kandemir-Cavas and Cavas, (2007) carried out a study stressing queues form when the demand for a service exceeds its supply, for many patients or clients, "waiting in queues for a service is annoying" (Obamiro, 2003) or is a "negative experience" (Scotland, 1991).

The unpleasant experience of waiting in line can often have a negative effect on the rest of a clients experience with a particular organization. "The way in which managers of organizations address the waiting time issue is critical to the long term success of their organizations." (Davis et al, 2003). Waiting causes not only inconvenience, but also frustration to people's daily lives. Often, customers may be discouraged from pursuing valuable services by a sheer length of the waiting line. At other times, waiting might even cause the customer to delay or miss important events.

The efficiency of waiting systems is one of factors that influence student's or client's perceptions on service quality. The waiting time problem is inevitable in cases of random requests thus, providing the capacity for a sufficient service is needed, but it is involving high costs. "This is the premise from which the queuing theory starts in designing service systems." (Alecu, F, 2004).

Bolanle (2011) carried out a study stressing the importance of queuing theory to the problem of port congestion in order to enhance sustainable development of Nigeria ports. Nigeria Ports are characterized with incessant congestion problem in the recent past and this has resulted in diversion of ships scheduled for Nigeria Ports to other neighboring country ports which has caused the country to lose a lot of revenue. The effectiveness of a Port is contingent upon loading and unloading of ships. The traffic movement through a port is a complex phenomenon because of the random nature of the arrival and service time of the ships. This requires a systematic approach in port planning and management. Queuing model was applied to the arrival and services pattern which causes the problems of congestion and proffer solutions to the problem areas. It was also used to predict the average arrival rate of ships to Tin Can Island Port and the average service rate per ship in a month. The study found out that the number of berth in Nigeria port is adequate for the traffic intensity of vessels but other factors leading to port congestion were also identified through the content analysis of the interview conducted with stakeholders at the port.

Chin (2007) investigated the submittal review/approval process and used queuing theory to determine the major causes of long lead times. Under his study, he explored the underlying causes of waiting in a process flow and found the improvement methods from the queuing perspective.

Joel Zhang Laifu (2000) has evaluated the performance of single-channel and Multiple channels queues using the discrete-event simulation technique. The input to the simulators is based on live data. A customer can hop to a shorter queue but the service time needed by the customers in the queue may be longer thus resulting in an even longer waiting time.

Opara-Nadi (2005) insisted that customers want fast checkout systems and retailers are always searching for ways to improve store checkout systems. To begin the study used a pilot project with 10 shoppers. The study compared the cashier checkout and the electronic self checkout systems. Data for the study were collected by observations of checkout processes at Wal-Mart Super Centers in the Jackson, Mississippi, area. Formulated research questions were statistically tested employing the independent samples t-tests and the chi square test for independence. Results of these analyses showed that consumers preferred the cashier checkout system to the electronic self-checkout system, although shoppers also want to learn how to use the new self-checkout technology. A random sampling technique was used by the study for a period of 2 weeks for three stores. 90 customers were selected from each of the two checkout systems. Information was obtained from responses and observations. Data was assembled, coded and analyzed using SPSS 12.0 for windows. Six (6) hypotheses were tested and analyzed using independent samples t-tests.

"In today's competitive business environment, the modern society is progressively turning into a service dominating one. Customer satisfaction and service operation capabilities have shown how to provide an organization a competitive advantage in the marketplace and this has consequently led to an increasing importance in service operations management. As a result, waiting has drawn great attention to all business operation management specialists."(Bonga Wellington Garikai, January 2014.)

Traditionally, a queue is studied in the perspective of operations research, using mathematical models to determine the efficiency of the queue under particular settings. However, it has been shown that it solves only part of the problem, the efficiency of the process, while the application of these results to real-world service operational settings is restricted because it does not take human factors into consideration.

The study to be undertaken JKUAT student finance office is based on the understanding that most of these difficulties can be managed by using queuing model to determine the waiting line performance such as: average arrival rate of customers, average service rate, system utilization factor, and the probability of a specific number of customers in the system.

By using questionnaires in our case study we are able to incorporate issues related to both the social and psychological perspectives in order to reduce the negative impact of waiting on customer satisfaction and perceived quality.

\section{Materials and Methods}

\subsection{Study Area}

A case study at JKUAT student finance office is being done whereby the empirical analysis of queuing theory being 
applied is conducted. Also questionnaires are issued to be filled by students in the queue to determine if they are satisfied by the service being offered and the waiting time.

\subsection{Project Assumptions}

The essence of queuing theory is that it takes into account the randomness of the arrival process and the randomness of the service process .In this project we will consider the dynamics of queues, or waiting lines. Where we will assume that;-

- Students arrive in some random manner at the service counters and independent of other arrivals.

- That upon arrival they wait in a queue until it is their turn to be served.

- That once served they leave the system

- First come fist served basis used

- One queue multiple service station

- Arrivals are in accordance with Poisson process.

- The service times follow exponential distribution.

- The average service rate is faster than the average arrival rate

\subsection{Methodology}

The type of research being undertaken is applied research since we are trying to solve specific, practical questions; for policy formulation, administration and understanding of a phenomenon.

A queue is a waiting line (like customers waiting at a supermarket checkout counter); queuing theory is the mathematical theory of waiting lines. More generally, queuing theory is concerned with the mathematical modeling and analysis of systems that provide service to random demands.

A queuing model is an abstract description of such a system. Typically, a queuing model represents

- The system's physical configuration, by specifying the number and arrangement of the servers, which provide service to the customers,

- The stochastic (that is, probabilistic or statistical) nature of the demands, by specifying the variability in the arrival process and in the service process.

A queuing model of a system is an abstract representation whose purpose is to isolate those factors that relate to the system's ability to meet service demands whose occurrences and durations are random. Typically, simple queuing models are specified in terms of the arrival process the service mechanism and the queue discipline. The arrival process specifies the probabilistic structure of the way the demands for service occur in time; the service mechanism specifies the number of servers and the probabilistic structure of the duration of time required to serve a customer, and the queue discipline specifies the order in which waiting customers are selected from the queue for service. Selecting or constructing a queuing model that is rich enough to reflect the complexity of the real system, yet simple enough to permit mathematical analysis) is an art. The ultimate objective of the analysis of queuing systems is to understand the behavior of their underlying processes so that informed and intelligent decisions can be made in their management.

\subsubsection{Single-Queue Multiple Servers Model (M/M/c)}

The first $M$ refers to the fact that the inter-arrival time is Markov and the second is the fact that service distribution is exponential and hence markovian. Inside the finance office there is more than one account clerk(c) which suggests there are multiple servers attending to students over the window at any given time. The number of clerks attending to students may vary from time to time whereby it is mostly one.

The system models the flow of students as they arrive to form a single line, wait in the queue if the system is busy, receive service, and eventually leave. We focus only on the main queue and queuing model in use is illustrated in figure 1

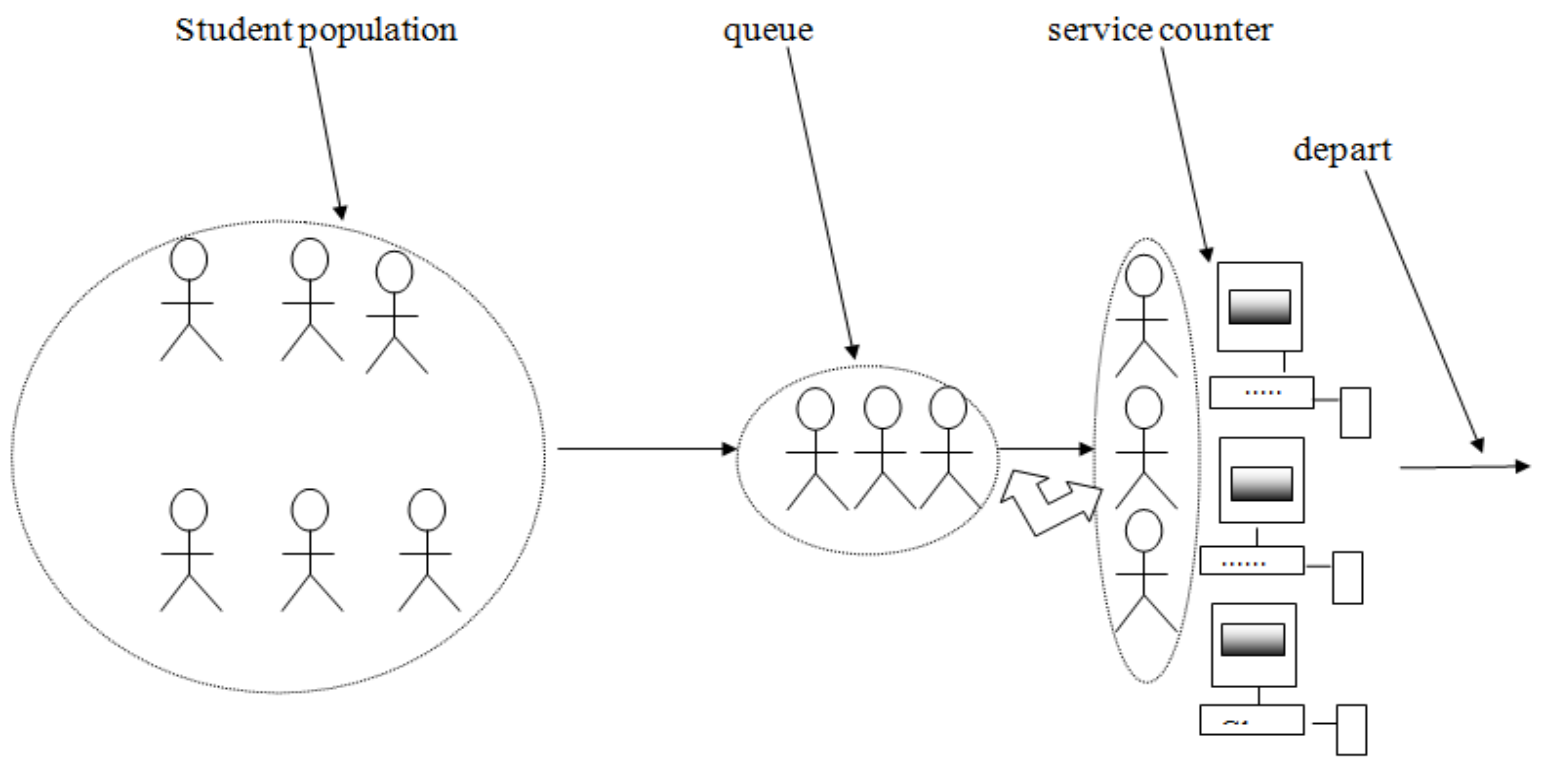

Figure 1. Single-queue Multiple Servers model $(M / M / c)$. 


\subsection{2. $M / M / c$ Model Formulas}

The following parameters are calculated, and their formulas have been presented;

$i$. Ar :Average arrival rate

$$
\mathrm{Ar}=\frac{\sum \text { inter arrival times }}{\text { number of students }}
$$

ii. Sr: average service rate

$$
\mathrm{Sr}=\frac{\sum \text { service time } s}{\text { number of students }}
$$

Average service rate (multiple servers) $=\mathrm{cSr}$

iii. $\quad \rho$ : System intensity (utilization) :

$$
\rho=\frac{\operatorname{Ar}}{\operatorname{Src}}
$$

iv. $\quad \boldsymbol{P}_{0}$ : Steady-state Probability of all idle servers in the system / Probability that there is no customer in the system

$$
P_{0}=\left[\sum_{n=0}^{c-1} \frac{r^{n}}{n !}+\frac{r^{c}}{c !(1-\rho)}\right]^{-1}
$$

Where $r=\frac{\lambda}{S r}$

v. $\mathrm{L}_{\mathrm{q}}$ : Average number of students in the waiting line(queue)

$$
\mathrm{L}_{\mathrm{q}}=\frac{r^{c} \rho}{c !(1-\rho)^{2}} * P_{0}
$$

vi. $\mathrm{L}_{\mathrm{s}}$ : Average number of students in the system

$$
\mathrm{L}_{\mathrm{s}}=\mathrm{L}_{\mathrm{q}}+\frac{\lambda}{\mathrm{Sr}}
$$

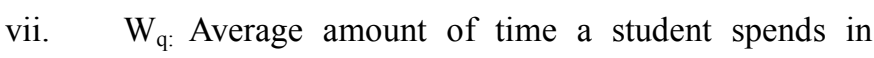
queue

$$
\mathrm{W}_{\mathrm{q}}=\frac{\mathrm{Lq}}{\mathrm{Ar}}
$$

viii. $\mathrm{W}_{\mathrm{s}}$ Average amount of time a student spends in the system

$$
\mathrm{W}_{\mathrm{s}}=\mathrm{W}_{\mathrm{q}}+\frac{1}{\mathrm{Sr}}
$$

It is worthy to note that the formulas can be applied only if $\mathrm{Sr}$ is greater than Ar. In other words, they can be applied only if $\mathrm{Ar} / \mathrm{Sr}<1$. Simply put, that is when the rate of arrivals is less than the rate of departures. Failing to meet this condition leads to a growing of the waiting line, because the service capacity is insufficient.

\subsubsection{Multinomial Logistic Regression}

Multinomial logistic regression is used to analyze relationships between a non-metric dependent variable and metric or dichotomous independent variables. It compares multiple groups through a combination of binary logistic regressions. Logistic model describes only the conditional distribution of the response given the predictors.

The group comparisons are equivalent to the comparisons for a dummy-coded dependent variable, with the group with the highest numeric score used as the reference group or baseline category. Multinomial logistic regression provides a set of coefficients for each of the two comparisons. The coefficients for the reference group are all zeros, similar to the coefficients for the reference group for a dummy-coded variable.

The overall test of relationship among the independent variables and groups defined by the dependent is based on the reduction in the likelihood values for a model which does not contain any independent variables and the model that contains the independent variables. This difference in likelihood follows a chi-square distribution, and is referred to as the model chi-square.

The significance test for the final model chi-square (after the independent variables have been added) is our statistical evidence of the presence of a relationship between the dependent variable and the combination of the independent variables.

Since the responses obtained in our questionnaire have more than two outcomes then our data follows a multinomial distribution where multinomial logistic regression would be used for modeling the queuing behavior in relation to customer satisfaction.

\subsection{Sample Size Determination}

Population sizes are considered either unlimited (essentially infinite) or limited (finite). When the number of customers or arrivals on hand at any given moment is just a small portion of all potential arrivals, the arrival population is considered unlimited, or infinite. In our case where students arrive to pay school fees at a large university is considered to be unlimited ( Heizer, Render, 2004)

In most statistical research studies, population parameters are usually unknown and have to be estimated from the sample. You want to determine the size of the sample how large or how small; therefore the sample should be of optimal size, not too large or not too small. Sample size should be large enough to give CI (confidence interval) of the desired width.

To determine the sample size one is required to specify the precision of the estimation desired. When a study is being made, sampling error arises and it is controlled by selecting a sample of adequate size. Usually, we use $95 \%$ of CI which is two tailed.

$$
\mathrm{n}=\frac{Z^{2} P q}{d^{2}}
$$

$\mathrm{n}=$ the desired sample size

$\mathrm{z}=$ the standard normal deviate at the realized confidence interval/Hence level 
$\mathrm{p}=$ the proportion in the target population estimated to have characteristics being measured.

$\mathrm{d}=$ the level of statistical significance.

$$
\mathrm{n}=\frac{1.96 * 1.96 *(0.5) *(0.5)}{0.0885 * 0.0885}=384
$$

\subsection{Sample Inclusion and Exclusion Criteria}

Only students that arrive in the queue, wait for their turn to be served and don't abandon the queue were included in the sample since dynamics of queues, queuing principles and project proposal assumptions must be observed, if any student did not adhere to all this during data collection was excluded.

\subsection{Sampling Strategy}

Simple random sampling strategy was used (probability sampling) since each student in the population has an equal and independent chance of being selected. Data was collected during the 1 st two weeks of the semester when students are reporting using the non-participant observation method.

The arrival times of all students as they arrive randomly were recorded, the time they start being served and eventually record the time they depart Questionnaires were issued to students randomly so that they can fill them during the queuing process if possible or anywhere in the university compound.

\subsection{Research Tools - Questionnaires and Data Collection and Recording}

The arrival times of each student arriving in the queue and time he /she leaves are recorded in form of a table.

\subsection{Questionnaire Technique Discussion}

A questionnaire was designed to collect specific data on the service time and customer satisfaction as shown in appendix 1. It was to be very rich with data for the behavior of customers in relation to the operations of the department with reference to serving time and serving queues. The questionnaire comprised of 12 questions, which were deemed enough to explore the need for the research and helped to answer some of the research questions.

Sex and year study of students was asked just to show the distribution of the clients. It was assumed that the behavior of males and females are different with respect to the needs.

The year study of the students is a crucial variable. It was included so as to check the level of awareness of the students. It is assumed that the quality of the information we obtain from highly educated is of higher grade than the one from less educated.

To confirm the origin or causes of serving queues at the office, the people approaching the office were asked. It was assumed that when customers arrive in groups, it automatically imposes pressure on the serving staff and hence longer queues arise. When customers arrive one by one, it relieves pressure and it is likely to have shorter queues.

Customers were asked if they are satisfied with the service time so as to determine their level of satisfaction with service offered. How do they behave if service time takes longer i.e. if they abandon the queue or even jump the queue?

They were also asked what solutions should be undertaken to reduce waiting time problem, how the service offered at the office compares to other offices and most importantly how quality of service offered compares to other organizations.

\section{Data Analysis and Modeling}

\subsection{Data}

The data was collected on the first two weeks of the semester for 384 students as was proposed during sample size determination in 3.4. Simple random sampling strategy was used (probability sampling) since each student in the population has an equal and independent chance of being selected by using the non-participant observation method. By using sample inclusion and exclusion criteria in 3.5 as was proposed 98 students were excluded from the data that was analyzed.

\subsection{Empirical Analysis of the Queuing Model (R Output Summary)}

By using the $\mathrm{M} / \mathrm{M} / 1$ model formulas, data for 286 students was analyzed using $\mathrm{R}$ software by running code as shown in appendix 2 .Table 4.2 shows the results obtained for the various parameters that were calculated.

Table 1. Model empirical analysis.

\begin{tabular}{ll}
\hline Efficiency parameters & Status quo $\mathbf{C}=\mathbf{1}$ \\
\hline $\mathrm{AR}$ & 22 students $/ \mathrm{hr}$ \\
$\mathrm{Sr}$ & 23.66897 students $/ \mathrm{hr}$ \\
$\mathrm{P}$ & $92.94872 \%$ \\
$\mathrm{~L}_{\mathrm{q}}$ & 12.25233 students \\
$\mathrm{L}_{\mathrm{s}}$ & 13.18182 students \\
$\mathrm{W}_{\mathrm{q}}$ & $33.41545 \mathrm{~min}$ \\
$\mathrm{~W}_{\mathrm{s}}$ & $35.95041 \mathrm{~min}$ \\
$\mathrm{P}_{0}$ & $7.051282 \%$ \\
\hline
\end{tabular}

From the $\mathrm{M} / \mathrm{M} / \mathrm{c}$ queuing model of which the arrival rate $\mathrm{A}_{\mathrm{r}}$ is 22 students per hour and there is a single server and service rate $S_{r}$ is 23.67 students per hour. This shows that the rate of serving is higher than the rate of which the customers are coming, implying that there is a bit of efficiency on the serving of customers.

The account clerks are found to be very busy i.e. $92.95 \%$ $\mathrm{p}$, hence the system is in use most of the time and hence the probability of account clerks being idle $\mathrm{P}_{0}$ is $7.05 \%$

There are 12.25 students in the queue $\mathrm{L}_{\mathrm{q}}$ waiting to be 
served and 13.18 students $L_{s}$ in the entire system.

A student waits in the queue $\mathrm{W}_{\mathrm{q} 33.41545} \mathrm{~min}$ to be served and $35.95041 \mathrm{~min}$ Ws in the entire system to be served. This is a very long period of time for a customer to wait to be served.

\subsection{Efficiency Analysis}

The accounts department mainly uses the single server model that is an $\mathrm{M} / \mathrm{M} / 1$ Queuing model has been identified.
However, for efficiency purposes, it is worth to assume a multi-server being used by the same department so as to compare the efficiency levels. To compare, the study has proposed an $\mathrm{M} / \mathrm{M} / 2$ and $\mathrm{M} / \mathrm{M} / 3$ model. It is worth mentioning that the multi-server model comes with an additional cost to the university and hence cost and benefit analysis will be required. The efficiency parameters for the three models are shown in Table below.

Table 2. Efficiency analysis.

\begin{tabular}{llll}
\hline Efficiency parameters & Status quo $\mathbf{C}=\mathbf{1}$ & $\mathbf{C = 2}$ & $\mathbf{C = 3}$ \\
\hline $\mathrm{A}_{\mathrm{r}}$ & 22 students $/ \mathrm{hr}$ & $22 \mathrm{students} / \mathrm{hr}$ & $22 \mathrm{students} / \mathrm{hr}$ \\
$\mathrm{S}_{\mathrm{r}}$ & $23.66897 \mathrm{students} / \mathrm{hr}$ & $23.66897 \mathrm{students} / \mathrm{hr}$ & $23.66897 \mathrm{students} / \mathrm{hr}$ \\
$\mathrm{P}$ & $92.94872 \%$ & $46.47436 \%$ & $30.98291 \%$ \\
$\mathrm{~L}_{\mathrm{q}}$ & 12.25233 students & 0.2560629 students & 0.1099538 students \\
$\mathrm{L}_{\mathrm{s}}$ & $13.18182 \mathrm{students}$ & 1.18555 students & $1.039441 \mathrm{students}$ \\
$\mathrm{W}_{\mathrm{q}}$ & $33.41545 \mathrm{~min}$ & $0.6983535 \mathrm{~min}$ & $0.2998739 \mathrm{~min}$ \\
$\mathrm{~W}_{\mathrm{s}}$ & $35.95041 \mathrm{~min}$ & $3.233319 \mathrm{~min}$ & $2.834839 \mathrm{~min}$ \\
$\mathrm{P}_{0}$ & 0.07051282 & 0.3913312 & 0.3654267 \\
\hline
\end{tabular}

Table 4.3 shows the efficiency parameters under t8hree different queuing models. By using the system utilization parameter, it has changed significantly from $92.72 \%, 46.47 \%$ to $30.98 \%$ for the $\mathrm{M} / \mathrm{M} / 1, \mathrm{M} / \mathrm{M} / 2$ and $\mathrm{M} / \mathrm{M} / 3$ consecutively. This shows that as more servers are introduced (this may be in form of more queue lines to various servers), then the department becomes less busy.

Considering also the length of the queue moving from $\mathrm{M} / \mathrm{M} 1$ through to $\mathrm{M} / \mathrm{M} / 3$ a reduction in queue size is noticed from 12.25233 students, 0.2560629 students and 0.109953 students.

All other parameters has supported that moving to a multiserver benefits the customers in terms of time they wait to be served, from $35.95041 \mathrm{~min}, 3.23331 \mathrm{~min}$, to $2.834839 \mathrm{~min}$

The probability that there is no student (zero customers) in the queue increases as the number of servers increases. For $\mathrm{M} / \mathrm{M} / 1$ model $\mathrm{P} \quad(\mathrm{n}=0)$ is 0.07051282 , for $\mathrm{M} / \mathrm{M} / 2$ is 0.3913312 and for $M / M / 3$ is 0.3654267 . However the rate of the increase in probability from a lower model to a higher model falls.

\subsection{Conclusion}

This is an awful long period of time to wait to be served given the amount of time it takes to wait in the queue is $33.41545 \mathrm{~min}$ and the large number of students waiting to be served this shows why there are usually very long queues during opening date and end of the semester when they want to clear their outstanding balances..

This indicates that the model in use is not effective at all times and especially at the start and the end of semester when the students really need the services of the finance department which affects vital activities such as student registration and exams.

\subsection{Questionnaire Results Analysis}

Appendix 1 shows a questionnaire conducted by the study in an effort to achieve one of the objectives of the study and making it clear the significance of the study. 395 questionnaires were dispatched to the students of which there were non-respondents and 384 were responded, which is a good number to obtain useful information.

By using a box plot as shown in graphs in figure 1, figure 2 and figure 3 both males and females mainly arrive either in pairs or groups respectively, both genders are not happy with the waiting time and would rather pay school fees over the course of the semester so as to avoid long queues at the start or final weeks of the semester.1st years mainly pay fees at the 1 st week or later which could be because of reporting date and the fact that they are new.

Due to the waiting problem the males tend to abandon the queue a few times while females are less tolerant and abandon the queue many times. This is reflected by how they try to solve the problem whereby males go away and come back the same day while females prefer to come for the service another day. The 4th years tend to take more extreme measures whereby they actually jump the queue which explains why they don't abandon the queue many times.

Both genders in all the years of study rate the service rate poorly and think it can be improved by increasing the staff and working harder. 

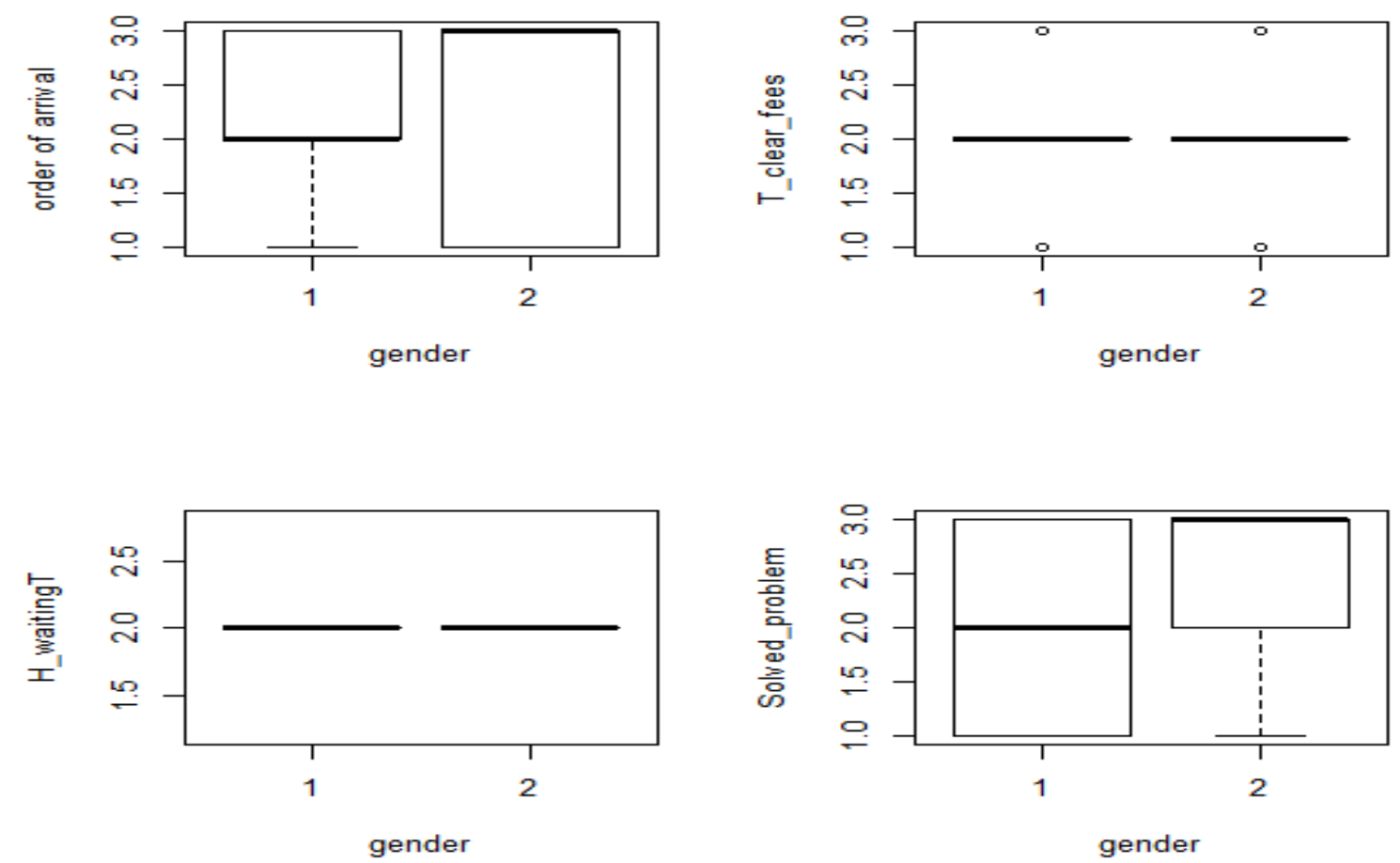

Male $=1$ female $=21^{\text {st }} y r=12^{\text {nd }} y r=23^{\text {rd }} y r=34^{\text {th }} y r=4$

Figure 2. box plot 1 .

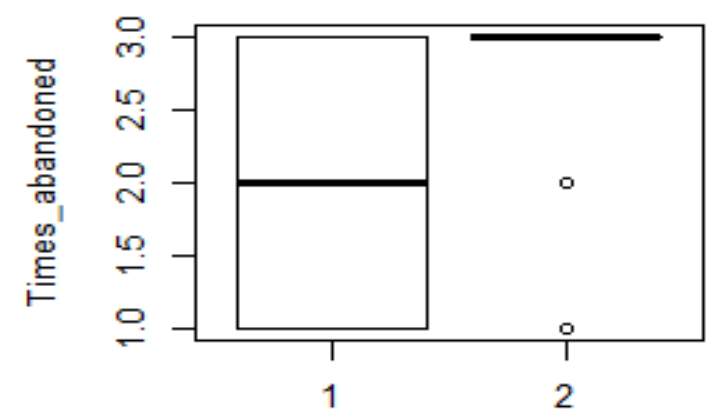

gender

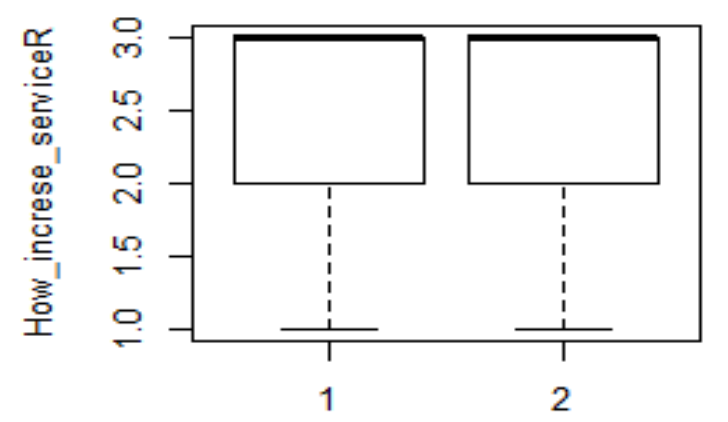

gender

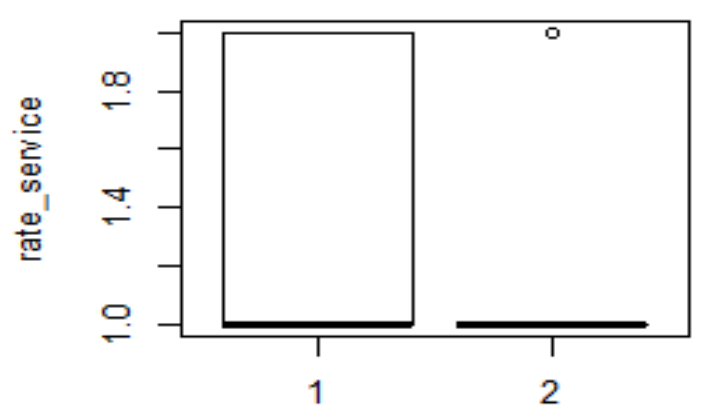

gender

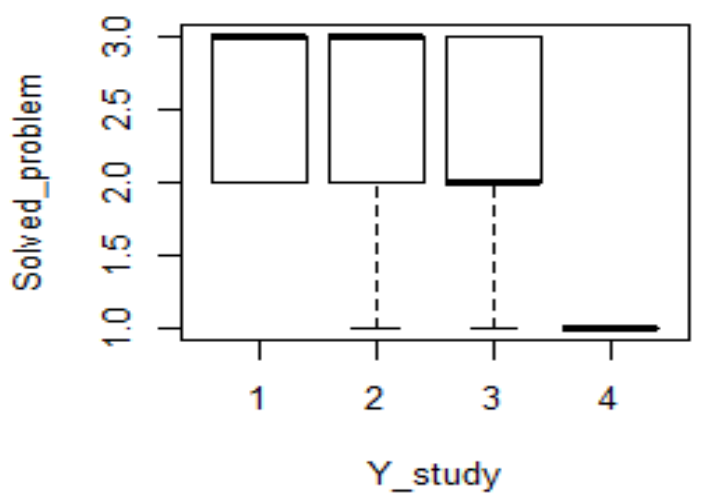

Male $=1$ female $=21^{\text {st }} y r=12^{\text {nd }} y r=23^{\text {rd }} y r=34^{\text {th }} y r=4$

Figure 3. box plot 2. 

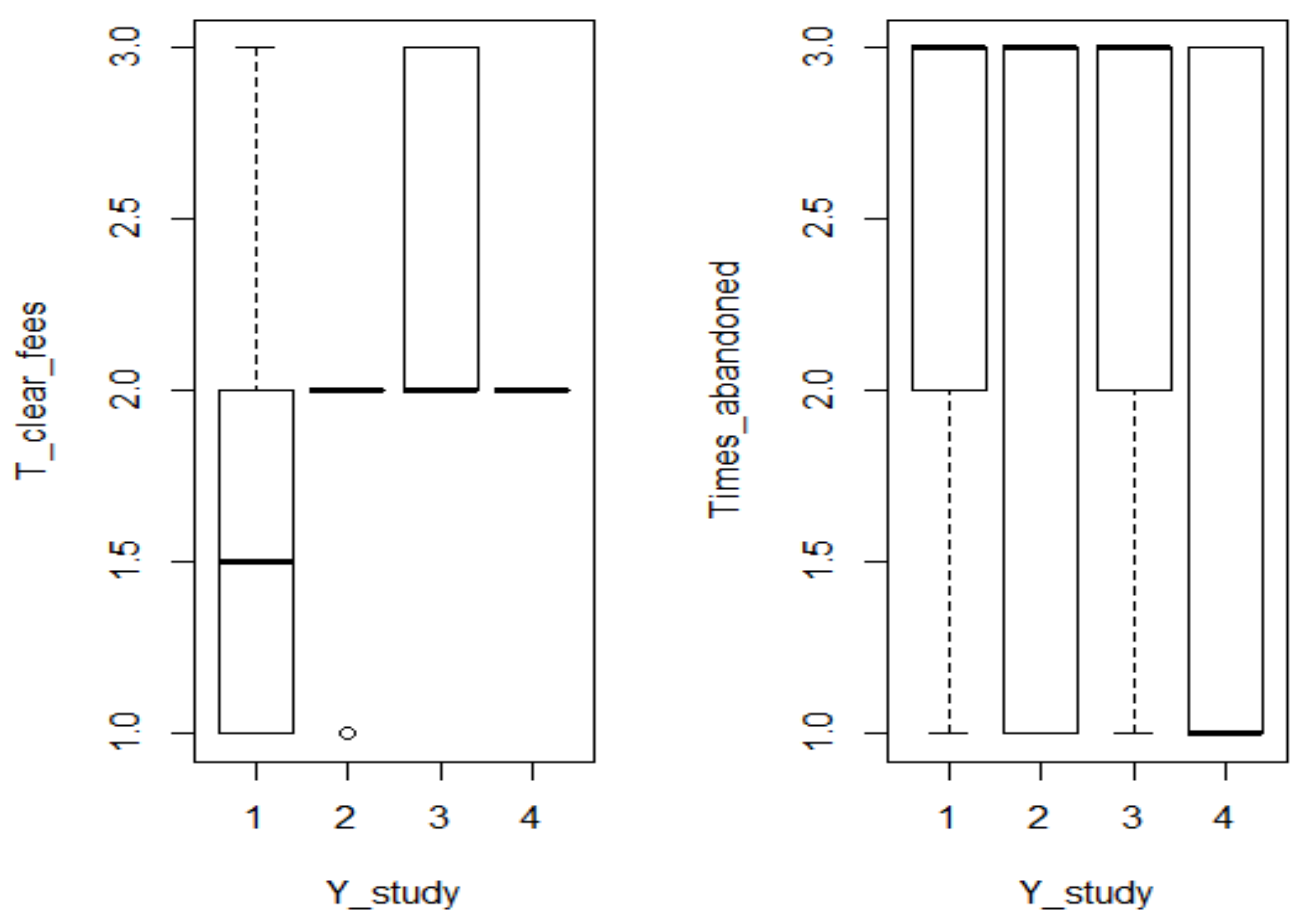

Male $=1$ female $=21^{\text {st }} y r=12^{\text {nd }} y r=23^{\text {rd }} y r=34^{\text {th }} y r=4$

Figure 4. box plot 3 .

\subsection{Modeling the Queue Behavior}

Response variables

- How students solved queuing problem (y2)

- Times students abandoned the queue (y4)

Predictor variables

- Gender (x1),

- Year of study (x2)

\subsection{Output}

This is obtained by analyzing the questionnaire responses by using multinomial logistic regression so as to model the queuing behavior which enables us to determine the level of customer satisfaction. The variables in 4.5 are regressed.

\subsubsection{Model 1}

How students solved queuing problem (y2).

Table 3. Model 1 Likelihood ratio tests.

\begin{tabular}{lllll}
\hline Effect & $\mathbf{- 2}$ log likelihood of reduced model & chi-square & d.f & Sig \\
\hline Intercept & 17.0504 & 0.000 & 0 & 2 \\
Gender(x1) & 205.488 & 188.434 & 6.0001 \\
Year of study(x2) & 491.996 & 474.942 & 6 & 0.0001 \\
\hline
\end{tabular}

P-value of gender $(x 1)=0.0001<0.05$

$\mathrm{P}$-value of year of study $(\mathrm{x} 2)=0.0001<0.05$

Both the yr of study and gender are statistically significant and hence both factors determine how students solve the queuing problem

This collaborates evidence obtained from the box plot where 4Th yrs solve queuing problem by jumping the queue and also females are less tolerant and solve the problem by abandoning the queue completely only to come back another day while males tend to come back on the same day.

Table 4. Final model 1

\begin{tabular}{llllll}
\hline Model & $\mathbf{- 2} \log$ likelihood of reduced model & chi-square & d.f & Sig \\
\hline intercept only & 546.283 & 0.0 & 0 & 0.0001 \\
Final & 17.054 & 529.299 & 8 & 0.0001 \\
\hline
\end{tabular}

In this analysis, the probability of the model chi-square (529.299) was 0.0001 , less than the level of significance of
0.05. The null hypothesis that there was no difference between the model without independent variables and the 
model with independent variables was rejected. The existence of a relationship between the independent variables and the dependent variable was supported. Hence both gender and year of study are significant.

\subsubsection{Model 2}

Times abandoned $(\mathrm{y} 4)$

Table 5. Model 2 Likelihood ratio tests.

\begin{tabular}{lllll}
\hline Effect & $\mathbf{- 2}$ log likelihood of reduced model & chi-square & d.f & Sig \\
\hline Intercept & 21.708 & 0.000 & 0 & \\
Gender(x1) & 274.083 & 252.376 & 2 & 0.0001 \\
Year of study(x2) & 329.334 & 307.626 & 6 & 0.0001 \\
\hline
\end{tabular}

P-value of gender $(\mathrm{x} 1)=0.0001<0.05$

$\mathrm{P}$-value of year of study $(\mathrm{x} 2)=0.0001<0.05$

Both Gender and year of study are statistically significant since p-value is less than 0.05 and hence gender influences the number of times a student abandons the queue which collaborates evidence obtained from the box plot that females are less tolerant and tend to abandon the queue more times than males.

Table 6. Model 2 Final.

\begin{tabular}{lllll}
\hline Model & $\mathbf{- 2} \log$ likelihood of reduced model & chi-square & d.f & Sig \\
\hline intercept only & 410.488 & 0.0 & 0 & 0.0001 \\
Final & 21.708 & 388.780 & 8 & 0.0001 \\
\hline
\end{tabular}

In this analysis, the probability of the model chi-square (388.780) was 0.000 , less than the level of significance of 0.05 . The null hypothesis that there was no difference between the model without independent variables and the model with independent variables was rejected. The existence of a relationship between the independent variables and the dependent variable was supported. Hence both gender and year of study are significant.

\section{Summary}

By doing an empirical analysis we are able to find the arrival rate $\mathrm{Ar}$ is 22 students per hour, service rate $\mathrm{Sr}$ is 23.67students per hour, The account clerks are found to be very busy i.e. $92.95 \%$ p, hence the system is in use most of the time and hence the probability of account clerks being idle $\mathrm{P}_{0}$ is $7.05 \%$

There are 12.25233 students in the queue Lq waiting to be served and 13.18182 students Ls in the entire system.

A student waits in the queue $\mathrm{Wq} 33.41545 \mathrm{~min}$ to be served and $35.95041 \mathrm{~min} \mathrm{Ws}$ in the entire system to be served.

Efficiency analysis is also carried out by increasing the number of servers c whereby we are able to find efficiency parameters under three different queuing models. By using the system utilization parameter, it has changed significantly from $92.95 \%, 46.47 \%$ to $30.98 \%$ for the $\mathrm{M} / \mathrm{M} / 1, \mathrm{M} / \mathrm{M} / 2$ and $\mathrm{M} / \mathrm{M} / 3$ consecutively which shows that the system becomes less busy. Considering also the length of the queue moving from M/M1 through to $\mathrm{M} / \mathrm{M} / 3$ a reduction in queue size is noticed from 13.18182 students, 0.2538053 students and 0.1091518 students.

All other parameters has supported that moving to a multi-server benefits the customers in terms of time they wait to be served, from $35.95041 \mathrm{~min}, 3.233319 \mathrm{~min}$, to

\section{$2.834839 \mathrm{~min}$}

By modeling queuing behavior using results obtained from the questionnaire we are able to establish that gender and year of study influences the queuing behavior which confirms evidence showed using the box plot that 4 th years solve the waiting problem by jumping the queue while 1 st 2nd and 3rd year go away and come back same day or another day.

Both genders are not happy with the waiting time and would rather pay school fees over the course of the semester so as to avoid long queues at the start or final weeks of the semester. They also rate service rate poorly and think it can be improved by increasing the staff and working harder.

\section{Conclusion}

The students wait in the queue for 33.4 minutes to be served which is a long period of time to wait to be served. The queuing system in use is not efficient since it creates a queuing problem to such an extent that some students choose to jump the queue to solve the problem, others solve it by abandoning the queue and coming back the same day mainly males but females abandon the queue completely only to come for the service another day.

This implies that the students are not satisfied by service offered which also confirms evidence obtained from the answers responded in the questionnaire and the queuing behavior analysis.

\section{Recommendation}

So as to enhance the efficiency of the system during busy times the university administration should;

Increase the number of account clerks attending to the 
students which would reduce the waiting time in the queues

Divide the queue into several queues whereby there is a specific one handling the many students making inquiries which seem to make those students paying school fees wait for longer periods of time.

Improve the payment system so that when students make payments in the different banks is reflected in the school system faster and the fee structures are updated quickly by the clerks and send to student accounts(student portal) so that students don't come to the queues to confirm their fee balances (make inquiries) thus reducing size of the queue.

\section{Appendix 1 Questionnare}

This questionnaire serves to gather data for a study in partial fulfillment of an MSC degree with the Jomo Kenyatta University of Agriculture and Technology undertaken by Sammy Kariuki Mwangi. The data collected is not used for any other purposes, other than the said.

1. Sex

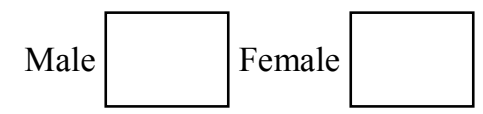

2. Year of study

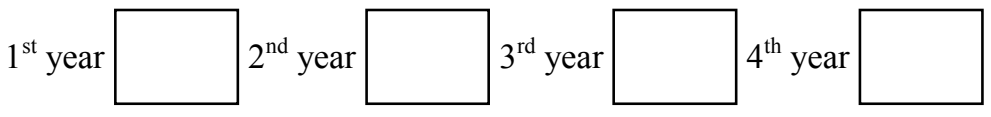

3. When you visit the finance office, how many will you be mostly?

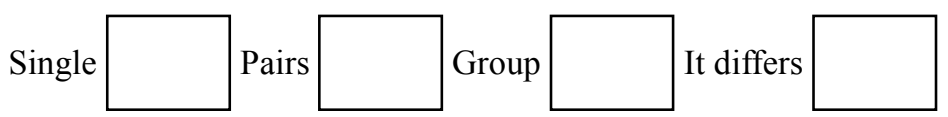

4. When do you normally clear your school fees?

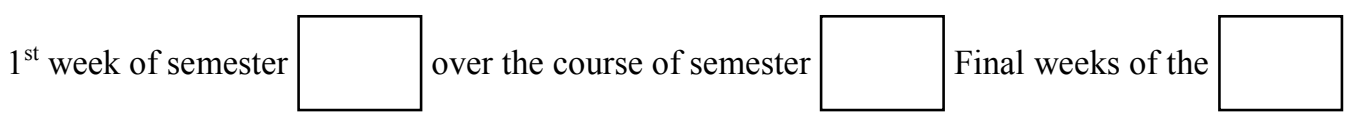

Semester

5. Are you happy with the serving time?

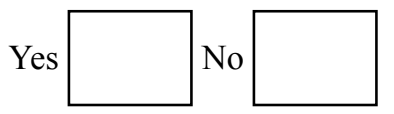

6. How do you rate the serving time?

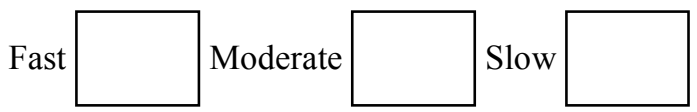

7. Have you ever turned away due to longer time being taken to be served?

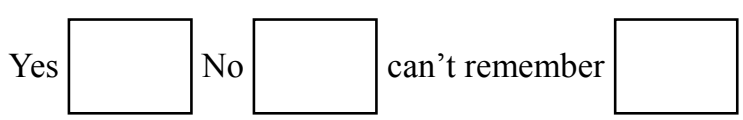

8 . If yes to 7 , how many times have you done such?

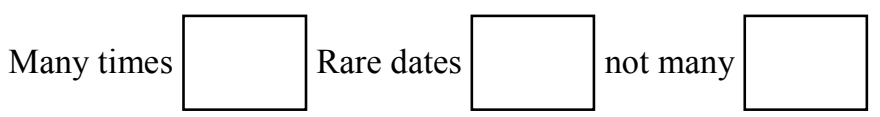

9. If yes to 7 , how have you solved the issue?

Jumped the queue $\longrightarrow$ went and came back on same day 
Went away and came another day

10. What do you think they should do to increase serving time?

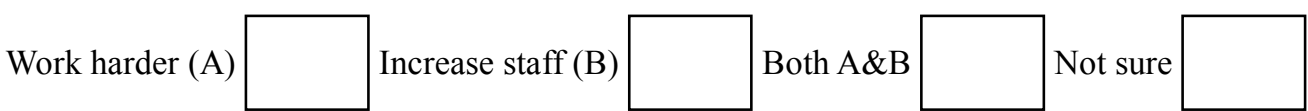

11. Comparing with other departments, how do you rate the said in terms of serving time.

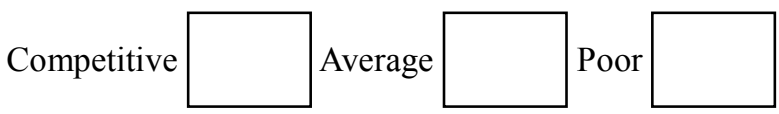

12. Comparing with other organizations, how do you rate the said in terms of serving time.

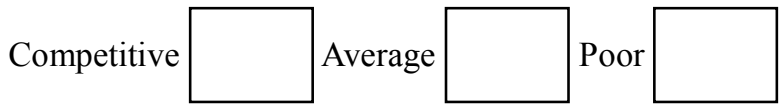

\section{Appendix 2: Program Code}

Questionnaire analysis (modeling queue behavior)

queue<-read.csv("C: \\projo \|project1.csv",header=T)

queue

$\mathrm{y}<$-queue\$order_of_arrival

$\mathrm{y}$

y1<-queue\$T_clear_fees

$\mathrm{y} 1$

y $2<$-queue\$Solved_problem y2

y3<-queue\$H_waitingT

$\mathrm{y} 3$

y4<-queue\$Times_abandoned

y4

y5<-queue\$rate_service

y5

y6<-queue\$How_increse_serviceR

y6

$\mathrm{x} 1<$-queue\$Gender

$\mathrm{x} 1$

$\mathrm{x} 2<$-queue\$Y_study

$\mathrm{x} 2 \operatorname{par}(\mathrm{mfrow}=\mathrm{c}(1,2))$

boxplot(y x1,xlab="gender",ylab="order of arrival")

boxplot(y1 x1,xlab="gender",ylab="T_clear_fees")

boxplot(y3 x1,xlab="gender",ylab="H_waitingT")

boxplot $(y 2 \sim x 1, x l a b="$ gender",ylab="Solved_problem")

boxplot(y4 x1,xlab="gender",ylab="Times_abandoned")

boxplot(y5 x1,xlab="gender",ylab="rate_service")

$\left.\mathrm{R}^{\prime \prime}\right)$

boxplot(y6 x1,xlab="gender",ylab="How_increse_service

boxplot(y2 x2,xlab="Y_study",ylab="Solved_problem") boxplot(y x2,xlab="Y_study",ylab="order of arrival")

boxplot(y1 x2,xlab="Y_study",ylab="T_clear_fees")

boxplot(y4 x2,xlab="Y_study",ylab="Times_abandoned")

boxplot(y5 x2,xlab="Y_study",ylab="rate_service")

Empirical analysis of queuing model

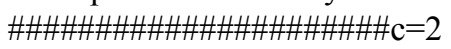

arrivalrate $=60 /(780 / 286)$

arrivalrate

$1<$-arrivalrate

1 servicerate $=60 /(725 / 286)$

servicerate

$\mathrm{m}=$ servicerate

$\mathrm{m}$

$\mathrm{c}=2, \mathrm{c}$

$\mathrm{m} 1=2 * \mathrm{~m}, \mathrm{~m} 1$

Systemintensity $=1 / \mathrm{m} 1$

Systemintensity

$\mathrm{r}<-1 / \mathrm{m}$

$\mathrm{r}$

$\mathrm{p} 0<-$

$\left(\mathrm{r}^{\wedge} 0 /\right.$ factorial $(0)+\mathrm{r}^{\wedge} 1 /$ factorial $(1)+\left(\mathrm{r}^{\wedge} 2 /(\right.$ factorial $(2) *(1-$

Systemintensity)) $))^{\wedge}-1$

p0

$\mathrm{lq}<-\left(\mathrm{r}^{\wedge} 2 *\right.$ Systemintensity/(factorial $(2) *(1-$

Systemintensity)^2))*p0

lq

$1 s<-l q+r$

1s

wq $<-$ lq $/ 1$

wq

wq*60

ws $<-w q+1 / m$

WS

ws*60

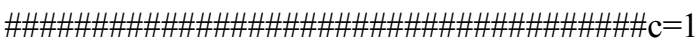

arrivalrate $=60 /(780 / 286)$

arrivalrate

$1<$-arrivalrate

1

servicerate $=60 /(725 / 286)$

servicerate

$\mathrm{m}=$ servicerate

$\mathrm{m} \mathrm{c}=1, \mathrm{c}$

$\mathrm{m} 11=1 * \mathrm{~m}$

m11

Systemintensity $1=1 / \mathrm{m} 11$

Systemintensity1 
$\mathrm{r}<-1 / \mathrm{m}, \mathrm{r}$

$\mathrm{p} 01<-\left(\mathrm{r}^{\wedge} 0 /\right.$ factorial $(0)+\left(\mathrm{r}^{\wedge} 1 /(\right.$ factorial $(1) *(1-$

Systemintensity 1$))))^{\wedge}-1$

p01

lq1<-( $\mathrm{r}^{\wedge} 1 *$ Systemintensity $1 /($ factorial $(1) *(1-$

Systemintensity 1$\left.\left.)^{\wedge} 2\right)\right)^{*} \mathrm{p} 01$

lq1

ls $1<-\mathrm{lq} 1+\mathrm{r}, \mathrm{ls} 1$

wq1<-lq1/1,wq1

$\mathrm{wq} 1 * 60$

ws $1<-$ wq $1+1 /$ m ,ws 1

ws $1 * 60$

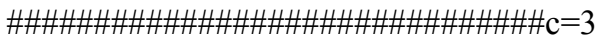

arrivalrate $=60 /(780 / 286)$

arrivalrate

$1<$-arrivalrate

1

servicerate $=60 /(725 / 286)$

servicerate

$\mathrm{m}=$ servicerate, $\mathrm{m}, \mathrm{c}=3, \mathrm{c}, \mathrm{m} 3=3 * \mathrm{~m}, \mathrm{~m} 3$

Systemintensity $3=1 / \mathrm{m} 3$

Systemintensity 3

$\mathrm{r}<-1 / \mathrm{m}, \mathrm{r}$

p03<-

$\left(\mathrm{r}^{\wedge} 0 /\right.$ factorial $(0)+\mathrm{r}^{\wedge} 1 /$ factorial $(1)+\mathrm{r}^{\wedge} 2 /$ factorial $(2)+\left(\mathrm{r}^{\wedge} 3 /\right.$ (facto

$\operatorname{rial}(3)^{*}(1-$ Systemintensity 3$\left.\left.\left.)\right)\right)\right)^{\wedge}-1$

p03

lq3<-( $\mathrm{r}^{\wedge} 2 *$ Systemintensity $3 /($ factorial $(2) *(1-$

Systemintensity3)^2) $*$ p03

$\operatorname{lq} 3$

$1 \mathrm{~s} 3<-\mathrm{lq} 3+\mathrm{r}$

ls3

wq $3<-l q 3 / 1$

wq3

wq $3 * 60$

ws $3<-w q 3+1 / m$ ws3

ws $3 * 60$

\section{References}

[1] Agresti, Laura A. Thompson (1996) "An Introduction to Categorical Data Analysis". New York: John Wiley \& Sons, Inc.

[2] Amole Bilqis Bolanle,(2011), "Application of Queuing theory to port congestion problem in Nigeria",European Journal of Business and Management 3 (8), 2011 www.iiste.org ISSN 2222-1905 (Paper) ISSN 2222-2839

[3] Azmat Nafees, (June 2007), Queuing theory and its application: analysis of the sales checkout operation in Ica supermarket, Department of Economics and Society ,M. Sc., University of Dalarna, Hogloskan Dalarna, Sweden

[4] Banks, J.Carson, Nelson, B. L., Nicol, D. M. (2001), DiscreteEvent System Simulation, Prentice Hall international series, 3 rd edition, p24-37

[5] Daisi Famule Festus (2010), “Analysis Of M/M/1 Queuing Model With Applications To Waiting Time Of Customers In Banks", Global Journal of Computer Science and Technology, 10 (13): (Ver. 1.0).

[6] Davis M. M, Aquilano M. J. N, Chase B. R (2003), "Fundamentals of Operations Management", Boston: McGrawHill Irwin, Fourth Edition.

[7] Erlang A.K. (1948), "On the rational determination of the number of circuits". In The life and works of A.K.Erlang. Brockmeyer E., Halstrom H.L. and Jensen A., eds. Copenhagen: The Copenhagen Telephone Company.

[8] Gregory E. Opara-Nadi,(2005), "Electronic Self-checkout System Versus Cashier Operated System: A Performance Based Comparative Analysis”, Capella University, May, 2005.

[9] Heizer, Render, (2004), "Operations Management -WaitingLine Models Module D," Prentice Hall, Inc, Upper Saddle River, N.J. USA.

[10] János Sztrik, (January , 2010), "Queuing theory and its applications, A Personal View", International Conference on Applied Informatics, Proceedings of the 8th conference,Vol.1.pp.9-30, Eger, Hungary

[11] J.DeLayne Stroud,(December, 2014 ) "Basic sampling Strategies:Sample vs Population data ",http: // www. isixsigma. com/tools-templates/sampling-data/ basic-sampling-strategiessample-vs-population-data/

[12] Jensen, Paul A. (2004), "Queuing models," Operations Research Models and Methods, www.me.utexas.edu/ jensen/ORMM/models/unit/queue/index .html

[13] J.S. (1997), "Regression Models for Categorical and Limited Dependent Variables". Thousand Oaks, CA: Sage.

[14] Kandemir-Caues, C and Cauas, L (2007), "An Application of Queuing Theory to the Relationship between Insulin Level and Number of Insulin Receptors", Turkish Journal of Biochemistry, 32 (1): 32-38. 
[15] Muhammad Marsudi, Hani Shafeek,(January 7 - 9, 2014) "The Application of Queuing Theory in Multi-Stage Production Line", Proceedings of the 2014 International Conference on Industrial Engineering and Operations Management Bali, Indonesia,

[16] Obamiro, J.K. (2003), “Application of Queuing Model in Determining the Optimum number of Service Facility in Nigerian Hospitals", M. Sc. Project submitted to Department of Business Administration, University of Ilorin, Nigeria

[17] Palash Sahoo, (May, 2011)," The Monitoring of The Network Traffic Based on Queuing Theory.” M.Sc., National Institute of Technology, Orissa, India.

[18] Prabhu, N. U. (1997), Foundations of Queuing Theory. Dordecht, Netherlands: Kluwer Academic Publishers Ritchie J and Lewis J (2003), 'QualitativeResearch Practice: A Guide for Social Science Students and Researchers'. Sage publications, London.

[19] S cotland, R., (1991), "Customer Service: A Waiting Game", Marketing, pp 1-3.1991

[20] Wellington Garikai Bonga, (January 2014)," An empirical analysis of the queuing theory and customer satisfaction: application in small and medium enterprises - a Case study of croc foods restaurant." $\mathrm{PhD}$, Atlantic International University, Zimbabwe.

[21] Zhang Laifu Joel 1 , Wei Jonathan .,Tay S. C,(2000), "Discrete- Event Simulation Of Queuing Systems",Proceedings of the Sixth Youth Science Conference, Ministry of Education, Singapore.(2000) 